\title{
Factors associated with occupational stress among nursing professionals in health services of medium complexity
}

\author{
Fatores associados ao estresse ocupacional entre profissionais de enfermagem em serviços de saúde de média complexidade
}

Factores asociados al estrés laboral entre profesionales de enfermería en servicios de salud de mediana complejidad

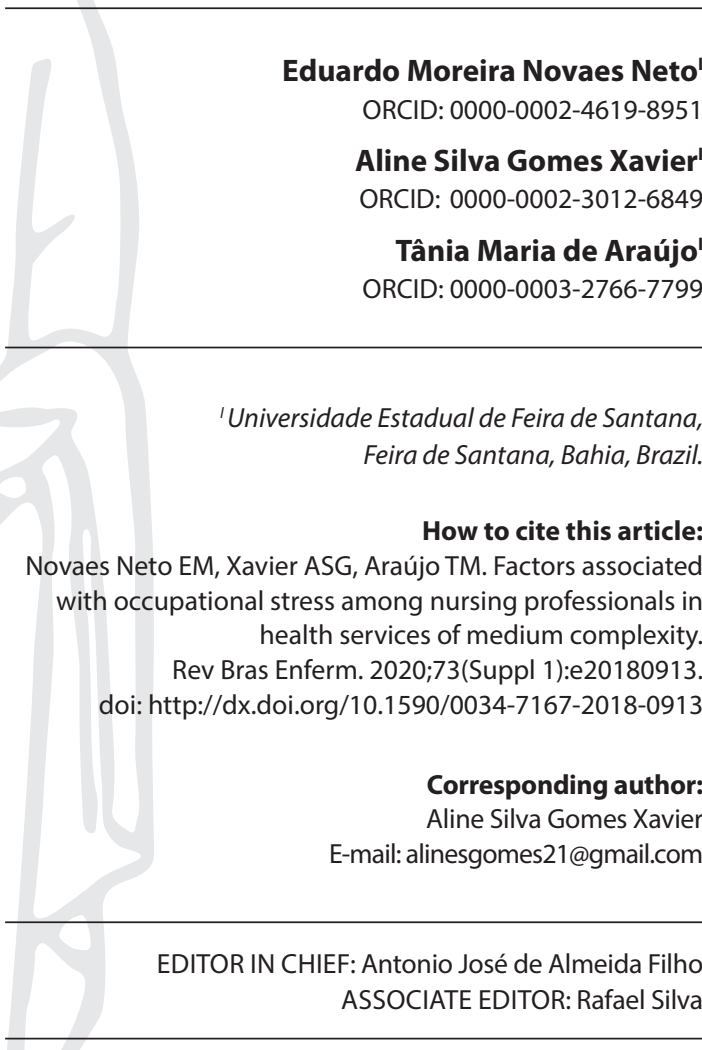

Submission: $04-04-2018$

Approval: 08-27-2019

\section{ABSTRACT}

Objective: To analyze the factors associated with occupational stress among nursing workers in health services of medium complexity. Methods: Epidemiological, cross-sectional, exploratory study. A randomly selected sample of 126 nursing professionals from medium complexity services in three cities in the state of Bahia (Santo Antônio de Jesus, Feira de Santana and Itabuna) was investigated. Data were collected in 2011 and 2012. The demandcontrol model proposed by Karasek was used to assess occupational stress. Simultaneous analysis of occupational stressors was performed using Poisson regression with robust variance. Results: The prevalence of occupational stress among nursing professionals was $77 \%$. Occupational stress was associated with the professional category of nursing technician $(p=0.01)$. Conclusion: The data indicates a concerning situation of exposure to occupational stressors, which requires coping strategies in order to protect the health of the worker. Descriptors: Mental Health; Work-Related Stress; Team Nursing; Health Personnel; Occupational Health.

\section{RESUMO}

Objetivo: Analisar os fatores associados ao estresse ocupacional entre trabalhadores de enfermagem dos serviços de saúde de média complexidade. Métodos: Estudo epidemiológico, transversal, exploratório. Investigou-se amostra, aleatoriamente selecionada, de 126 profissionais de enfermagem dos serviços de média complexidade de três municípios na Bahia: Santo Antônio de Jesus, Feira de Santana e Itabuna. Os dados foram coletados nos anos de 2011 e 2012. Para avaliar o estresse ocupacional, utilizou-se o modelo demanda-controle, proposto por Karasek. A análise simultânea dos fatores ocupacionais estressores foi feita com emprego de regressão de Poisson com variância robusta. Resultados: A prevalência de estresse ocupacional entre profissionais de enfermagem foi de $77 \%$. Estresse ocupacional associou-se à categoria profissional de técnico/a de enfermagem $(p=0,01)$. Conclusão: $O s$ dados evidenciam situação preocupante de exposição desse grupo a estressores ocupacionais, sendo necessária a adoção de estratégias de enfrentamento a fim de garantir proteção integral à saúde do/a trabalhador/a.

Descritores: Saúde Mental; Estresse Ocupacional; Equipe de Enfermagem; Trabalhador da Saúde; Saúde Ocupacional.

\section{RESUMEN}

Objetivo: analizar los factores asociados al estrés laboral entre trabajadores de enfermería de servicios de salud de mediana complejidad. Métodos: estudio epidemiológico, de diseño transversal y exploratorio. Se investigó una muestra de 126 profesionales de enfermería en tres municipios de Bahía. Los datos se recogieron durante los años 2011 y 2012. Para evaluar el estrés laboral, se utilizó el modelo demanda-control propuesto por Karasek. El análisis simultáneo de los factores laborales estresores se llevó a cabo mediante la regresión de Poisson con variancia robusta. Resultados: La prevalencia del estrés laboral entre profesionales de enfermería era del $77 \%$. Dicho estrés estaba asociado a la categoría profesional de técnico/a de enfermería $(p=0,01)$. Conclusión: Los datos demuestran la existencia de una situación preocupante en ese grupo, con exposición a estresores laborales, haciéndose necesario la adopción de estrategias de enfrentamiento a fin de garantizar una protección integral para la salud de los trabajadores.

Descriptores: Salud Mental; Estrés Laboral; Grupo de Enfermería; Personal de Salud; Salud Laboral 


\section{INTRODUCTION}

Stress is a state precipitated by the perception of stimuli that induce emotional arousal and disturb homeostasis, triggering an adaptation process characterized, among other alterations, by increased secretion of adrenaline and cortisol and several systemic manifestations that, if continuously experienced, may result in physiological and psychological disorders. The term stressor, in turn, defines the event or stimulus that causes or leads to stress ${ }^{(1)}$.

In the context of work, stress is related to situations when work demands exceed the ability of the worker to handle them, or when the conditions and resources available are insufficient to meet those demands. Thus, when work demands exceed the ability of the worker to adapt, we have the so-called occupational stress ${ }^{(2)}$.

When occupational stress is experienced on a daily basis, it causes physical or psychological tension that, in turn, can lead to dissatisfaction, disinterest, apathy and anger. Continuous and prolonged stressful situations generate several effects involving personal, social and economic repercussions. From an economic point of view, there is a decrease in work performance, leading to reduced productivity and increased costs, especially due to workers' health problems, increased absenteeism, larger number of work accidents and increased turnover ${ }^{(3)}$. Recent studies indicate a consistent relationship between stressful situations and various health effects: cardiovascular disease and hypertension (topic with long research tradition and with a significant body of empirical evidence on this association); mental health issues, especially depression and anxiety; and immune system problems, among other effects studied ${ }^{(4-5)}$.

Thus, surveillance of occupational stress is relevant to monitor the health situation and quality of life of workers, and to define actions that can reduce or eliminate stressors. This monitoring can be done using appropriate measurement tools.

There are several research models and instruments available in literature to evaluate occupational stressors. Among these models, one of the most used worldwide is the Demand-Control Model (MDC), which is based on psychosocial characteristics of work, highlighting the psychological demand of work activities and the worker's control over their work. The Job Content Questionnaire (JCQ) is the proposed instrument for measuring these dimensions $^{(6)}$. The main prediction of this model is that work performed under conditions of low control and high psychological demand (a situation called as high demand) represents a health risk and leads to physical and mental illness ${ }^{(6)}$.

The evaluation and monitoring of exposure to occupational stress, made possible by the use of instruments such as the JCQ, are particularly important in some groups of workers, such as nursing professionals, who are exposed to a variety of stressors in the workplace ${ }^{(3)}$. In their daily practice, they provide direct assistance to patients and are exposed to various risks related to work activities, which may lead to a variety of occupational stress situations. The constant contact with pain, suffering, despair, uncertainties, and other feelings resulting from the experience of illness favors stress ${ }^{(4,7)}$. The conditions in which these situations are experienced can help coping or, on the contrary, amplify their impact. If the conditions are precarious, unhealthy or unsafe, tension will increase, and so will stress. As inadequate conditions for nursing practice are frequent, according to what is consistently reported in the literature, nursing was classified by the Health Education Authority as the fourth most stressful profession in the public sector ${ }^{(8)}$. Nurses and nursing technicians have stressful professions, with extensive workload, responsibility for various sectors, and constant contact with the suffering and pain of patients and their families ${ }^{(9)}$.

Most of the available data on occupational stress among nursing workers is related to work in hospital settings. Few studies have focused on primary health care or medium complexity services. In Brazil's Unified Health System (SUS), medium complexity encompasses a set of actions and outpatient and hospital services that aim to address the main health problems of the population, with a clinical practice that requires specialized professionals and technological resources for diagnostic and therapeutic support and that corresponds to specialized care $^{(6)}$. In SUS, based on the idea of a hierarchical care network, medium complexity services are responsible for providing specialized services following the actions developed in primary health care (basic health and family health units).

This level of care involves several types of services, such as emergency care, specific assistance (focused on care and monitoring of diseases - e.g.: arterial hypertension, diabetes mellitus, cancer, sickle cell disease - or care to specific groups - women, older adults, workers), dental specialties and control of endemic diseases. In some of these services, such as in urgent care units, workers have to deal with unexpected situations, which constitute a risk factor for occupational stress ${ }^{(7)}$. In other services at this level of care, workers face complex situations that require complex resources, which are not always available, causing tension, suffering and anxiety ${ }^{(3)}$.

This study seeks to investigate occupational stressors in workers of medium complexity services. It is justified by the scarcity of studies that evaluated medium complexity services in Brazil, especially when considering their set and not only urgency and emergency services. It is also justified by the need to assess occupational stressors in this group, in order to promote interventions to avoid prolonged or continuous exposure to stressful situations. This is necessary because occupational health problems are an important public health issue. This study will provide a diagnosis of a given health and work situation. The results obtained might guide actions that can contribute to a better work performance of nursing professionals and decrease their exposure to stressful situations ${ }^{(7)}$. Therefore, results in this direction may represent an important health promotion strategy. In addition, considering that occupational stress can lead to various types of corporate problems (such as increased absenteeism and decreased productivity), decrease work-related quality of life and work accidents and even lead workers to leave the profession ${ }^{(2,8)}$, investments in research and in measures to reduce its occurrence are necessary.

Thus, the guiding question of this study was: what are the factors associated with occupational stress among nursing professionals in health services of medium complexity in the state of Bahia?

\section{OBJECTIVE}

To analyze the factors associated with occupational stress among nursing workers in health services of medium complexity in the state of Bahia. 


\section{METHOD}

\section{Ethical aspects}

All aspects of Resolution 466/2012 were followed. The Research Ethics Committee involving Human Beings of the State University of Feira de Santana evaluated and approved the research protocols. The professionals selected for the study were informed of the research objectives at the time of data collection and, after agreeing to participate, signed the Informed Consent Form (TCLE).

\section{Design, setting and period}

This is a cross-sectional epidemiological study part of the research project "Working, Employment and Health Conditions of Health Workers in Bahia", conducted in the Epidemiology Center of the State University of Feira de Santana, together with other state and federal universities of Bahia (UESC, UESB, UFRB and UFBA). Data was collected in 2011 and 2012. Equator guidelines were followed, through the instrument Strengthening the Reporting of Observational Studies in Epidemiology (STROBE).

The study sample consisted of 126 nursing professionals (nurses and nursing technicians) from medium complexity services of the cities Feira de Santana, Santo Antônio de Jesus and Itabuna. These cities were selected because they are located in different regions of Bahia and are important representatives of their regions. Feira de Santana is the second largest city in Bahia, with 617,528 inhabitants and located 108 km from Salvador. Santo Antônio de Jesus is located $187 \mathrm{~km}$ from Salvador and is considered the capital of the "Recôncavo Baiano", with a population of approximately 100,605 inhabitants. Itabuna is a city in the southern region of Bahia with a total area of $432,244 \mathrm{~km}^{2}$, located $426 \mathrm{~km}$ from the capital of Bahia, and with about 212,740 inhabitants.

Workers from all medium complexity services of the cities studied were considered eligible for the study. The following institutions are included: Emergency Care Units (UPA); Polyclinics; Reference Centers (Psychosocial Care Center (CAPS); Dental Specialties (CEO); Occupational Health (CEREST), services for STD/ HIV/AIDS, Diabetes Mellitus, Hypertension, Sickle Cell Anemia, Women's Health, Older Adult's Health, Sanitary Dermatology); Counseling \& Testing Center (CTA); Center for the Control of Endemic Diseases; Oncology Prevention Center; and Rehabilitation and Human Development Center.

\section{Sample, inclusion criteria}

The sample of the research project was defined through successive stages: a) a list of all active workers in primary and medium complexity services in the three cities was obtained; b) the sample size was estimated based on the total population and different health outcomes, choosing to define the number of workers based on the outcome with the largest sample size; c) after defining the sample size, the sample was stratified according to three factors - geographic area, level of care (basic and medium complexity care) and occupational group (seven occupational groups were established, one of them composed of nursing workers: nurses, nursing assistants and nursing technicians) -, and the sample was defined based on the percentage participation of each group by level of stratification established; $d$ ) After estimating the sample size for each stratum, the workers were randomly selected for the sample based on Epilnfo 6.04d random number generator. After the draft, the workers were contacted in their own workplaces, and up to three visits were made to identify the professionals and conduct the interview.

For this study, professionals were initially selected by level of care, with 1,348 workers from medium complexity services (824 in Feira de Santana, 306 in Itabuna and 218 in Santo Antônio de Jesus). Then, from the group of medium complexity workers who were drawn for inclusion in the study, a new sample was selected, including only the nursing professionals. Thus, only medium complexity nursing workers were included in this study. As already mentioned, the sample was selected based on the list of all workers, stratified by geographic area, level of care and occupational group.

In this study, 126 professionals (nurses, nursing assistants and technicians) were interviewed and composed the study population.

Inclusion criteria were professionals actively working during data collection. Those who were on vacation or sick leave during the fieldwork period were excluded.

\section{Study protocol}

A questionnaire constructed according to the literature review and tested in the pilot study was used for data collection. This questionnaire contained questions about lifestyle, household activities, working conditions, and psychosocial aspects of work, as well as sociodemographic and employment characteristics. The questionnaire was self-administered to nurses and applied by previously trained interviewers to nursing assistants and technicians. These different procedures were adopted to ensure the operability of the study.

The outcome variable of this study was occupational stress, assessed by the Demand-Control Model, proposed by Karasek and used in several countries ${ }^{(6)}$. Psychological demand is assessed by five items and job control by nine items (six related to use of skills and three to decision-making authority). These items are measured on a Likert-type scale (1: strongly disagree, 2: disagree, 3: agree, 4: strongly agree). The recommendations of the JCQ Center Manual (www.JCQCenter.org) were followed. The scores were dichotomized based on the median of each scale. Then, demand and control levels were combined, composing the four groups defined in the model (low strain, active work, passive work and high strain).

For purposes of analysis, occupational stress was associated with the groups of "high strain"(low control, high demand), "passive work" (low control, low demand) and "active work". "(high control, high demand). That is, professionals who were exposed to high demand and/or low control were considered exposed to occupational stress. Professionals in the group of "low strain" (high control, low demand) were considered as the reference group, without occupational stress.

The exposure variables investigated were: socio-demographic characteristics (gender, age, level of education, self-reported skin color, civil status, children), occupational characteristics (time of work, professional activity, employment relationship, monthly income in minimum wages, work shift, weekly hours of work, fulfillment of labor rights, other employment, job satisfaction, occupational violence) and lifestyle habits (physical activity, alcohol consumption, smoking, leisure activity). 


\section{Analysis of results and statistics}

Univariate, bivariate and multivariate analyzes were performed. In the univariate analysis, absolute and relative frequencies were estimated for each of the selected variables. In the bivariate analysis, the prevalence ratios were estimated by analyzing occupational stress according to the variables of interest.

The variables were selected for the multivariate model based on Pearson's chi-square test $\left(\mathrm{X}^{2}\right)$ or Fisher's exact test, considering a level of significance of $25 \%$, that is, all variables with $p \leq 0.25$ in the bivariate analysis were included in the multivariate model, regardless of the blocks (socio-demographic characteristics, occupational characteristics and lifestyle habits), considering the statistical significance of the bivariate analysis based on the $p$-value. The collinearity between variables was also assessed, aiming to avoid the inclusion of two variables measuring similar aspects in the multivariate model. This was done to avoid overfitting.

The selection of variables for multivariate model testing has been considered a necessary step, because it allows starting the analysis with a broad set of variables and maintaining those that may in fact be related to the event under study. On the other hand, more flexible statistical criteria are recommended for this process (with the use of $p$ values higher than the traditional $5 \%)^{(10)}$. Thus, this study started with a broad set of variables, and adopted $p \leq 0.25$ for the selection of variables. The variables selected in this step were then tested for the multivariate model.

Unconditional logistic regression was used in the multivariate analysis. The variables with statistically significant association at the $5 \%$ level remained in the final model. Prevalence was estimated using Poisson regression with robust variance. Accuracy of the final model was measured by the area under the ROC curve. The software used for data analysis was the Data Analysis and Statistical Software (STATA), version 12.0.

\section{RESULTS}

Among the 126 nursing workers of the medium complexity services included in the study, most were women (92.9\%), 35 years old or less (51.6\%), self-reported black or brown (81.6\%), with vocational technical degree $(43.1 \%)$, with a partner $(53.1 \%)$ and with children (64.3\%).

Regarding occupational characteristics, it was observed that most participants were nursing technicians (71.4\%), with temporary employment bond (66.4\%), without labor rights (81.0\%), with time of work of up to 10 years (65.9\%), who worked 40 weekly hours or less $(97.6 \%)$, in the daily shift $(69.1 \%)$ and who had an income of up to two minimum wages (53.6\%). More than half of the professionals reported having another paid job (56.0\%). Job satisfaction was reported by $68.3 \%$ and $76.2 \%$ had already witnessed occupational violence in the workplace.

Regarding lifestyle habits, the majority did not engage in physical activity $(74.0 \%)$, but engaged in leisure activities (88.1\%), did not smoke (96.0\%) and did not consume alcohol (64.0\%).

The prevalence of Occupational Stress (Table 1) among the nursing workers of the medium complexity services in Bahia, assessed by the Demand-Control Model, was $77.0 \%$. That is, $77 \%$ of professionals experienced stressful situations (low control or high psychological demand), either simultaneously (both at the same time) or separately (one or the other). The classification of high strain work, when both unfavorable situations (low control and high psychological demand) are present, encompassed $26.2 \%$ of the professionals.

The bivariate analysis of the association between sociodemographic characteristics and occupational stress (Table 2 ) included the following variables, selected according to the established criteria $(p<0.25)$ : female gender $(p=0.113)$, technical degree $(p=0.037)$, higher education degree $(p=0.03)$, having a partner $(p=0.010)$ and having children (0.244).

The variables selected for the bivariate analysis of the association between occupational characteristics and Occupational Stress (Table 03) were working as a nursing technician $(p=0.002)$, having temporary employment bond $(p=0.103)$ without labor rights $(p=$ 0.182 ) and having an income of up to two minimum wages $(p=0.196)$.

The analysis of association between lifestyle habits and Occupational Stress (Table 04) showed a statistically significant positive association only with lack of physical activity $(p=0.157)$.

After multivariate analysis (Table 05), the variable "professional activity - nursing technician" remained associated with Occupational Stress ( $P R=1.43 ; C l=1.067-1.914 ; p=0.017)$. The analysis of the final model was performed by estimating the area below the ROC curve, which had a value of 0.72 , indicating good discriminative ability.

Table 1 - Prevalence of Occupational Stress among nursing workers of medium complexity services $(\mathrm{N}=126)$, Brazil, Bahia, 2012

\begin{tabular}{lll}
\hline Occupational Stress & $\mathbf{n}$ & $\%$ \\
\hline Occupational Stress & & \\
$\quad$ Yes & 97 & 77.0 \\
No & 29 & 23.0 \\
Demand-Control Model & & \\
$\quad$ Low strain & 29 & 23.0 \\
Active work & 33 & 26.2 \\
Passive work & 31 & 24.6 \\
High strain & 33 & 26.2 \\
\hline
\end{tabular}

Table 2 - Frequency of Occupational Stress among nursing workers according to socio-demographic characteristics, Bahia, Brazil, 2012

\begin{tabular}{|c|c|c|c|c|c|}
\hline \multirow{2}{*}{$\begin{array}{l}\text { Socio-demographic } \\
\text { characteristics }(\mathrm{N})\end{array}$} & \multicolumn{4}{|c|}{ Occupational Stress } & \multirow{2}{*}{$\begin{array}{c}p \\
\text { value }\end{array}$} \\
\hline & Yes & $\%$ & No & $\%$ & \\
\hline \multicolumn{6}{|l|}{ Gender (126) } \\
\hline Men & 5 & 55.6 & 4 & 44.4 & \\
\hline Women & 92 & 78.6 & 25 & 21.4 & 0.113 \\
\hline \multicolumn{6}{|l|}{ Age (years) (126) } \\
\hline 35 years old or less & 51 & 78.5 & 14 & 21.5 & \\
\hline More than 35 years old & 46 & 75.4 & 15 & 24.6 & 0.684 \\
\hline \multicolumn{6}{|l|}{ Self-reported Skin Color (125)* } \\
\hline Black and brown & 80 & 78.4 & 22 & 21.6 & 0.363 \\
\hline White & 16 & 69.6 & 7 & 30.4 & \\
\hline \multicolumn{6}{|l|}{ Level of education $(123)^{*}$} \\
\hline Vocational Technical degree & 43 & 81.1 & 10 & 18.9 & 0.037 \\
\hline Higher education degree & 32 & 86.5 & 5 & 13.5 & 0.013 \\
\hline Master's degree & 20 & 60.6 & 13 & 39.4 & \\
\hline \multicolumn{6}{|l|}{ Civil status (126) } \\
\hline With a Partner & 42 & 71.2 & 17 & 28.8 & \\
\hline Without a partner & 85 & 82.1 & 12 & 17.9 & 0.010 \\
\hline \multicolumn{6}{|l|}{ Children (126) } \\
\hline Yes & 65 & 80.2 & 16 & 19.8 & 0.244 \\
\hline No & 32 & 71.1 & 13 & 28.9 & \\
\hline
\end{tabular}

Note: * Information lost due to lack of response (two workers in skin color and three in level of education). 
Table 3 - Frequency of Occupational Stress among nursing workers according to occupational characteristics, Bahia, Brazil, 2012

\begin{tabular}{|c|c|c|c|c|c|}
\hline \multirow{2}{*}{ Occupational Characteristics (N) } & \multicolumn{4}{|c|}{ Occupational Stress } & \multirow{2}{*}{$\begin{array}{c}p \\
\text { value }\end{array}$} \\
\hline & Yes & $\%$ & No & $\%$ & \\
\hline Professional Activity (126) & & & & & 0.002 \\
\hline Nurse & 21 & 58.3 & 15 & 41.7 & \\
\hline Nursing technician & 76 & 84.4 & 14 & 15.6 & \\
\hline Employment Bond $(125)^{*}$ & & & & & 0.103 \\
\hline Permanent & 29 & 69.0 & 13 & 31.0 & \\
\hline Temporary & 68 & 81.9 & 15 & 18.1 & \\
\hline Labor Rights (126) & & & & & 0.182 \\
\hline Yes & 16 & 66.7 & 8 & 33.3 & \\
\hline No & 81 & 79.4 & 21 & 20.6 & \\
\hline Time of Work (126) & & & & & 0.622 \\
\hline Up to 10 years & 65 & 78.3 & 18 & 21.7 & \\
\hline More than 10 years & 32 & 74.4 & 11 & 25.6 & \\
\hline Weekly work hours (125) & & & & & 0.674 \\
\hline 40 hours or less & 94 & 77.0 & 28 & 23.0 & \\
\hline More than 40 hours & 2 & 66.7 & 1 & 33.3 & \\
\hline Work shift (123) & & & & & 0.564 \\
\hline Day/Night & 63 & 71.4 & 22 & 25.9 & \\
\hline On-call & 30 & 78.9 & 8 & 21.1 & \\
\hline Income (125) & & & & & 0.196 \\
\hline Up to two minimum wages & 55 & 82.1 & 12 & 17.9 & \\
\hline More than two minimum wages & 42 & 72.4 & 16 & 27.6 & \\
\hline Other Employment (125) & & & & & 0.453 \\
\hline Yes & 52 & 74.3 & 18 & 25.7 & \\
\hline No & 44 & 80.0 & 11 & 20.0 & \\
\hline Job Satisfaction $(\mathrm{N}=126)$ & & & & & 0.718 \\
\hline Yes & 67 & 77.9 & 19 & 22.1 & \\
\hline No & 30 & 75.0 & 10 & 25.0 & \\
\hline Occupational Violence (126) & & & & & 0.344 \\
\hline Yes & 72 & 75.0 & 24 & 25.0 & \\
\hline No & 25 & 83.3 & 5 & 16.7 & \\
\hline
\end{tabular}

Note: * Information lost due to lack of response (two workers in employment bond, weekly work hours, income, other employment; and three workers in the work shift variable).

Table 4 - Frequency of Occupational Stress among nursing workers according to lifestyle habits, Bahia, Brazil, 2012

\begin{tabular}{lccccc}
\hline & \multicolumn{6}{c}{ Occupational Stress } & \multirow{p}{p}{} \\
Lifestyle Habits (N) & Yes & $\%$ & No & $\%$ & value \\
\hline $\begin{array}{l}\text { Physical Activity (111)* } \\
\quad \text { No }\end{array}$ & 58 & 81.7 & 13 & 18.3 & 0.157 \\
$\quad$ Yes & 28 & 70.0 & 12 & 30.0 & \\
Leisure Activity (126) & & & & & \\
$\quad$ Yes & 86 & 77.5 & 25 & 22.5 & \\
$\quad$ No & 11 & 73.3 & 4 & 26.7 & 0.720 \\
$\quad$ Smoking (125)* & & & & & \\
$\quad$ No & 92 & 76.7 & 28 & 23.3 & \\
$\quad$ Yes & 4 & 80.0 & 1 & 20.0 & 0.863 \\
Alcohol Consumption (125)* & & & & & \\
$\quad$ No & 63 & 78.8 & 17 & 21.2 & \\
$\quad$ Yes & 33 & 73.3 & 12 & 26.7 & 0.491 \\
\hline
\end{tabular}

Note: *Information lost due to lack of response (one worker in smoking, alcohol consumption; and 15 workers in physical activity).

Table 5 - Multivariate analysis using unconditional logistic regression of Occupational Stress among nursing workers of medium complexity services, Bahia, Brazil, 2012

\begin{tabular}{lccc}
\hline Variable & PR & $\mathbf{9 5 \% C l}$ & $\boldsymbol{p}$ value \\
\hline $\begin{array}{l}\text { Professional Activity } \\
\quad \text { Nurse }\end{array}$ & & & \\
$\quad$ Nursing technician & 1.00 & -- & -- \\
\hline
\end{tabular}

\section{DISCUSSION}

The results allowed identifying general characteristics of workers of medium complexity services in the cities studied. As observed in the present study, nursing is a female dominated profession, which is also evidenced by other studies conducted in $\mathrm{Brazi}^{(3,8-9)}$. In the group studied, most were women, black, nursing technicians, and with temporary employment relationships. These results are in accordance with a research conducted with health workers of a university hospital, which found similar sociodemographic characteristics ${ }^{(8)}$. Greater participation of women in the health sector, especially in nursing, has been evidenced ${ }^{(3-4)}$.

Regarding the outcome evaluated, measured by the demandcontrol model, the results showed a very high frequency of occupational stress in the studied population. More than $3 / 4$ of the group was exposed to situations of high psychological demand and/or low level of control over their own work. A study conducted with nursing professionals of emergency units in the state of Mato Grosso do Sul showed prevalence of occupational stress of $70 \%$, a percentage similar to that found in this study, demonstrating the severity of this outcome among these professionals $^{(3)}$. It is worth noting that, in the study mentioned ${ }^{(3)}, 32.1 \%$ of the participants were in the group of high strain and $8.1 \%$ in the group of passive work.

As already mentioned, workplace stress is associated with aspects of the organization, the administration and the work system and with the quality of human relationships ${ }^{(4)}$. Nursing work is complex and involves emotional tension and physical and mental exhaustion, which may contribute to stress. These inherent characteristics are even more stressful if the conditions of the work environment are unfavorable.

A review of the literature on work environment stressors among nursing professionals found that inadequate structure, excessive noise from the environment and the devices, understaffing and lack of resources were considered stress-inducing factors. In addition, feelings related to lack of professional recognition, job dissatisfaction and poor interpersonal relationships make work even more stressful. All these feelings might lead to symptoms of irritability, fatigue, sadness, drowsiness and social isolation, resulting in occupational stress ${ }^{(11)}$.

This study focused on the characteristics of stressful situations, as suggested in the demand-control model. This choice arises from the concern that continuous exposure to stress, as already mentioned, has significant impact on the physical and mental state of the nursing worker, and may increase difficulties in professional performance and activities of daily living. The health effects of stress are relevant and consistent in the literature $\mathrm{e}^{(3,8-9)}$. The results of a study with nursing professionals of nine emergency services $(\mathrm{N}=134)$ that analyzed the association between occupational stressors and self-reported health status attested to the deleterious effect of stressors: with models adjusted for different confounding factors, the results showed that workers subjected to all types of work stress (high strain, passive and active work) presented poorer self-rated health when compared to those under low strain; in high strain situations, the associations were very robust $(\mathrm{OR}=4.3$ a $\mathrm{OR}=7.8)$. This study did not address the association between stressors and health status; however, 
these results, which are associated with a population similar to the one studied here, reinforce the importance of monitoring sources of stress in the work environment, with special attention to what generates these situations.

The bivariate analyses showed associations between occupational stressors and socio-demographic characteristics (female gender, higher education degree - compared to master's degree, having a partner, having children and receiving less than two minimum wages), occupational characteristics (being a nursing technician, having a temporary employment relationship and lack of labor rights - vacations, days off) and lifestyle habits (lack of physical activity).

Aspects related to the roles and responsibilities attributed to women and men in societies give rise to different types of social experiences (whether in paid work or in domestic and family work) and, consequently, lead to different levels of exposure and health risks. The participation of women in the labor market did not reduce their domestic work. Thus, the work overload arising from double, sometimes triple shifts can lead to occupational stress ${ }^{(8-9,12)}$. A study on stress in nursing work pointed out that the multiple tasks performed by women, which, in addition to work overload, include household chores and caring for children, lead to feelings of helplessness and frustration, since they can not handle all the work required of them ${ }^{(8,12)}$. A study on gender issues, psychosocial characteristics of work and health status found more negative results among women than among men, especially regarding lack of opportunity for professional growth. This is a relevant information for nursing, since it is a female dominated profession ${ }^{(3)}$.

The analysis of the association between socio-demographic characteristics and occupational stressors indicates that professional workload is added to domestic work, increasing women's physical and mental exhaustion and reducing their forms of recovery (hours of sleep, leisure activities and rest). The family demands related to their partners and children increase the total working time (away from home and at home) and, in general, represent a "huge amount of invisible work" performed by women ${ }^{(12)}$. These findings, despite being a preliminary analysis stage in this study, point to the need to also consider domestic work when analyzing occupations mostly dominated by women. Thus, the total workload (professional and domestic) should be considered, since these two spheres may have factors that increase stress ${ }^{(9,12)}$.

The frequency of occupational stressors was higher among younger people. Negative indicators related to emotional exhaustion are more common among younger professionals, pointing to a relationship between age and professional experience and suggesting that younger people are more likely to experience work overload ${ }^{(3,13)}$.

The proportions of occupational stressors were similar when comparing professionals with higher education and technical degrees (both with very high levels of stress), but lower among those with a master's degree. This result reinforces the hypothesis that higher levels of training may help professionals to deal with work tensions and reduce the impact of stressors ${ }^{(13)}$. In the case of specialized health care, such as the one offered in medium complexity services, it is fundamental to be well qualified and up to date in order to meet the demands that arise. In contrast, being insecure, feeling outdated, or insufficiently prepared to deal with situations that involve someone else's well-being - in this case, situations requiring intervention for a problem with a high level of complexity - can lead to strain and tension, which are stress-inducing factors.

Working under precarious conditions, for example, with temporary employment and lack of labor rights, has been identified as a significant occupational stressor and health risk ${ }^{(14)}$. In medium complexity services in the cities studied, the predominant employment relationships were temporary, with no job stability. Lack of employment security and lack of labor rights (right to time off and paid vacation) are associated with two types of feelings: a constant concern with the possibility of keeping or losing their position and continuous and strenuous work, as periods of rest or relaxation are not guaranteed or preserved as desired and required. These feelings can generate relevant occupational stress.

The literature points out that physical activity reduces stress. Individuals who engage in regular physical activity have alternatives to relax and experience pleasant situations, usually in environments that are not their home or work. Intense work demands, such as situations involving pain and suffering, enhance the importance of alternatives for achieving physical and mental balance ${ }^{(13,15)}$.

When evaluated separately, all the variables mentioned above were associated with occupational stress, according to the criteria adopted. After multivariate analysis, only the professional activity (being a nursing technician) remained statistically associated with occupational stress.

This prominent finding of professional activity (being a nursing assistant or technician) as an occupational stressor can be explained by the scarcity of human resources and materials for this type of work in health institutions. The imbalance between resources available and work demands is more prominent in services with higher level of complexity. Specialized services often require more resources and materials, as well as up-to-date technology. Thus, as the demand for equipment and resources in medium complexity services is higher, some work activities may be more stressful than others. The closer the worker is to direct patient care, the more this imbalance is experienced, since patients can blame the professional for precarious situations and the professionals themselves may have a feeling of personal failure when they can not do their work as it should be done.

As nursing technicians are often responsible for direct patient care, stressful situations may be more frequent for these professionals, as observed in this study. Other characteristics, such as high workload, night shifts, difficult interpersonal relationships and conflicts between work and household activities, can add to this tension and have intense negative effects. The last aspect mentioned should be particularly noted, since most nursing workers are women and are also responsible for domestic work, which causes psychological overload and, consequently, leads to occupational stress ${ }^{(16)}$.

High and medium complexity work environments are considered stressful. In these settings, professionals have to respond to considerable demands related to high complexity care, which requires readiness and heavy responsibilities, which in turn cause emotional distress and problems arising from care practice ${ }^{(17)}$. High responsibility (high psychological demand) and low autonomy, aspects evaluated in this study as occupational stressors, are 
related to situations with various stressful factors. Services that respond to urgent and emergent demands require skills, such as agility, ability to think and act quickly, and ability to solve emerging problems ${ }^{(18)}$. It is a context in which time is limited and activities are intense and require quick actions in order to avoid the imminent risk of death ${ }^{(18)}$. All the particularities of the work process in these units can contribute to the emergence of occupational stress. This may be more intense according to the characteristics of the different professionals involved in this type of service, as mentioned above ${ }^{(18)}$.

It should also be mentioned that occupational stressors in nursing work may be being affected by the privatization of hospital units (when the management of health units in transferred from the government to the private sector). This process causes job insecurity, reduces wages and makes working conditions even more precarious, for example, by reducing staff and care materials, as entrepreneurs are more interested in maximizing profit than in the health of the worker or the quality of the nursing care provided ${ }^{(18)}$.

\section{Study Limitations}

Some limitations of this study must be considered. One of the most important problems is related to the type of epidemiological design (cross-sectional), which makes it impossible to determine a temporal relation, and answers to some questions may be altered due to the presence of occupational stress. The healthy worker effect may also have occurred, since only tenacious and healthy workers tend to remain at work. Workers who experience a high level of stress may have left the profession or taken a leave of absence. In this case, this bias may lead to an underestimation of the prevalence of the outcome. Prevarication bias may also have occurred, as the workers might have been embarrassed to answer some items of the questionnaire or, based on their judgment of what was the desired answer, may have omitted data or issued false information. However small, information loss due to lack of response must also be considered as a study limitation.

It is also important to carefully consider the result obtained, which showed high proportions of occupational stress. The criteria adopted to identify stressful situations were very broad, including the experience of high psychological demand and/or low control. Therefore, workers who experienced one of these two conditions were classified as exposed to stress. This criterion was very sensitive, but it may also have classified false positive individuals. As this was a first approach to the subject, identifying the existence of stressful conditions was relevant and really attested that the problem exists and deserves attention. Future studies should restrict the classification of stressors (being more specific) in order to identify more vulnerable groups that may experience, for example, simultaneous exposure to a set of criteria.

It is also worth noting that the absence of significant associations of variables that were relevant in the bivariate analysis but did not remain in the final model may have been due to the small sample size $(\mathrm{N}=126)$. The sample analyzed was representative of nursing professionals from medium complexity services of the cities participating in the study; however, it may have been insufficient to apprehend existing associations. Therefore, the absences of association in this study need to be carefully analyzed.

\section{Contributions to the areas of nursing, health or public health}

As a contribution, this study provided a diagnosis of occupational stressors affecting the physical and mental health of nursing professionals of medium complexity services in the state of Bahia, considering the particularities of the work process at this level of care. This is one of the few studies conducted in Brazil with a specific focus on the set of services included in medium complexity care (not addressing only a specific service, such as urgent and emergent care, for example). Therefore, it provides initial information for more detailed future investigations.

\section{CONCLUSION}

Occupational stress is highly prevalent among nursing professionals in medium complexity services in the cities studied in Bahia. The results indicated that the most significant stressful situations occur among professionals with a technical degree. Therefore, special attention should be directed to this group. In addition, the fact that this study highlights the factors associated with occupational stress among nursing professionals indicates the need for actions focused on this problem, seeking to ensure comprehensive workers' health.

Coping strategies and measures to reduce sources of stress based on the reorganization of the work environment are urgently needed in order to protect workers' health. The characteristics of the work are factors that can lead to stressful situations. However, they are also factors that can be modified to prevent this outcome.

\section{REFERENCES}

1. Hirschle ALT, Gondim SMG, Alberton GD, Ferreira, ASM. Estresse e bem-estar no trabalho: o papel moderador da regulação emocional. Rev Psicol Org Trabalho [Internet]. 2019 [cited 2019 Jun 10];19(1):532-40. Available from: https://dx.doi.org/10.17652/rpot/2019.1.14774

2. Argüeso MS, González MI. Trabajo y sociedad [Internet]. Facultad de Humanidades, Ciencias Sociales y de la Salud, Universidad Nacional de Santiago del Estero; 2015 [cited 2017 Nov 14]. Available from: http://www.scielo.org.ar/scielo.php?script=sci_arttext\&pid=S1514-687

3. Theme-Filha MM, Costa MAS, Guilam MCR. Occupational stress and self-rated health among nurses. Rev Latino-Am Enfermagem [Internet]. 2013 [cited 2017 Oct 20];21(2):475-83. Available from: https://doi.org/10.1590/S0104-11692013000200002.

4. Araújo TM, Santana AIC, Almeida MMG, Santos KOB. Psychosocial aspects of work and common mental disorders among health workers: contributions of combined models. Rev Bras Epidemiol [Internet]. 2016 [cited 2017 Nov 20];19(3):645-57. Available from: http://dx.doi. org/10.1590/1980-5497201600030014 
5. Hove H, Wahrendorf M, Siegrist J. Occupational position, work stress and depressive symptoms:a pathway analysis of longitudinal SHARE. J Epidemiol Community Health [Internet]. 2015 [cited 2017 Dec 02];69(5):447-52. Available from: http://dx.doi.org/10.1136/jech-2014-205206

6. Karasek RA. Job demands, job decision latitude, and mental strain: implications for job redesign. Adm Sci Q [Internet]. 1979 [cited 2017 Nov 30];24(2):285-308. Available from: http://www.jstor.org/stable/2392498?origin=crossref

7. Sousa AFL, Queiroz AAFLN, Oliveira LB, Moura MEB, Batista OMA, Andrade D. Social representations of biosecurity in nursing: occupational health and preventive care. Rev Bras Enferm [Internet]. 2016 [cited 2017 Oct 10];69(5):864-71. Available from: http://dx.doi. org/10.1590/0034-7167-2015-0114.

8. Lua ID, Araújo TM, Santos KOB, Almeida MMG. Factors associated with common mental disorders among female nursing professionals in primary health care. Psicol Reflex Crit [Internet]. 2018 [cited 2019 Jun 15];31:1-14. Available from: http://dx.doi.org/10.1186/ s41155-018-0101-4

9. Araújo TM, Aquino EMG, Santos CO, Aguiar L. Aspectos psicossociais do trabalho e distúrbios psíquicos entre trabalhadoras de enfermagem Rev Saúde Pública [Internet]. 2003 [cited 2017 Dec 11];37(4):424-33. Available from: http://dx.doi.org/10.1590/\$0034-89102003000400006.

10. Hosmer DW, Lemeshow S. Applied logistic regression. [S.I.]: John Wiley and Sons, 2000.

11. Moraes-Filho IM, Almeida RJ. Estresse ocupacional no trabalho em enfermagem no Brasil: uma revisão integrativa. Rev Bras Promoc Saúde [Internet]. 2016[cited 2018 Feb 15];29(3):447-54. Available from: https://periodicos.unifor.br/RBPS/article/view/4645

12. Sousa LP; Guedes DR. A desigual divisão sexual do trabalho: um olhar sobre a última década. Estudos Avançados [Internet]. 2016 [cited 2018 Feb 15];30(87):123-140. Available from: http://dx.doi.org/10.1590/S0103-40142016.30870008

13. Rocha SV, Barbosa AR, Araujo TM. Leisure-time physical inactivity among healthcare workers. Int J Occup Med Environ Health [Internet]. 2017 [cited 2018 Feb 20];31(3):251-60. Available from: http://dx.doi.org/10.13075/ijomeh.1896.01107

14. Silva JLL da, Soares R da S, Costa F dos S, Ramos D de S, Lima FB, Teixeira LR. Psychosocial factors and prevalence of burnout syndrome among nursing workers in intensive care units. Rev Bras Ter Intensiva [Internet] 2015 [cited 2017 Nov 13];27(2):125-33. Available from: http://www.gnresearch.org/doi/10.5935/0103-507X.20150023

15. Ribeiro RPE, Marziale MHP, Martins JT, Galdino MJQ, Ribeiro PHV. Occupational stress among health workers of a university hospital. Rev Gaúcha Enferm[Internet]. 2018 [cited 2019 Jun 04];39:e65127. Available from: http://dx.doi.org/10.1590/1983-1447.2018.65127

16. Scholze AR, Martins JT, Do ML, Cruz Robazzi C, Do M, Fernandez C, et al. Occupational stress and associated factors among nurses at public hospitals. Cogitare Enferm [Internet]. 2017 [cited 2018 Jan 28];22(3):e50238. Available from: http://www.saude.ufpr.br/portal/ revistacogitare/wp-content/uploads/sites/28/2017/07/50238-212397-1-PB.pdf

17. Martins JT, Bobroff MCC, Andrade AN, Menezes GD. Emergency nursing team: occupational risks and self protection. Rev Enferm UERJ [Internet]. 2014 [cited 2018 Jan 28];22(3):334-40. Available from: http://www.facenf.uerj.br/v22n3/v22n3a07.pdf

18. Azevedo BDS, Nery AA, Cardoso JP. Occupational stress and dissatisfaction with quality of work life in nursing. Texto Contexto Enferm [Internet]. 2017 [cited 2018 Jan 28];2017;26(1):e3940015. Available from: http://dx.doi.org/10.1590/0104-07072017003940015 